\title{
The reversal of the B̈̈REN-BEEREN merger in Austrian Standard German
}

\author{
Marjoleine Sloos \\ University of Groningen, Tongji University
}

In language change, a reversal of a merger is generally considered to be impossible, since after two sounds have become fully merged, they are no longer distinct, so no phonetic or phonological cues exist that could reverse this process. This article investigates such an 'impossible' merger reversal: the split of the BäREN vowel (orthographically represented by $<\ddot{a}>$ or $<$ äh $>$ ) and the BEEREN vowel (orthographically represented by $\langle\mathrm{e}\rangle$, $<\mathrm{ee}\rangle$ or $\langle\mathrm{eh}\rangle$ in Austrian Standard German. We investigated a corpus of spoken data, measured the acoustic properties of the vowels, and determined the degree of the merger (by computing Pillai scores) for younger and older speakers. It turns out that the two sounds were formerly merged, but currently a split can be observed as an ongoing process. This paper argues that language contact with Standard German as it is spoken in Germany motivates the ongoing reversal. Since the BÄrEN vowel is also subject to substantial variation in German Standard German, in order to get the split right, Austrian speakers are likely to invoke orthographical knowledge. We will consider the mental representations of this sound, including the graphemic representations from an Exemplar-theoretical viewpoint.

Keywords: Austrian Standard German, Bären vowel, Exemplar Theory, merger, orthography, reversal, unmerger

\section{Reversal of a Merger}

In a merger, two different sounds converge on a single sound. It is usually assumed that a merger, if completed, cannot be reversed for the logical reason that after merging no phonetic or phonological cues exist that can serve as a means for reversal. Even in dialect contact, in which dialect $M$ has the merger and dialect $S$ has the split, $\mathrm{M}$ speakers will not learn the split, for they are not able to perceive the categorical distinction; if speakers try to reverse a merger, they will not get it 
right (Labov, 1994). However, a few cases have been reported in which unmerging does seem to occur. Labov (1994) attributes this reversal to the occurrence of lexical loanword strata - explicitly excluding other potential reasons, such as orthography. There seem to be alternative circumstances in which a reversal of a merger could occur, however. Maguire $(2008: 332,333,357)$ claims that reversals can occur "given the right social context", that is, under pressure of e.g. orthography, dialect contact and/or dialect levelling, and hypercorrection. In fact, under these circumstances, vowel mergers may be considered as incomplete, i.e. as near-mergers. In case of such a near-merger, some speakers merge two vowels and other speakers don't. It is also possible that vowels are still phonologically distinct, but that the speakers do not perceive the difference (Trudgill \& Foxcroft, 1978). It may even be the case that speakers merge in production, but still perceive a split in the speech of others (Hay, Warren, \& Drager, 2006). Whether vowels are completely merged or not is difficult to establish, and subtle differences which might not be apparent first, may turn out to be cues for perceptual distinction on closer inspection (Watt, 1998).

This article investigates the BäREN-BEEREN merger in Austrian Standard German. The Bären-BEEREN merger is a well-known merger in Standard German studies (Hove, 2002; Kleiner \& Knöbl, 2011; König, 1989; Sloos, 2013; Spiekermann, 2008) and most pervasive in Austria and the Low-German area. Austrian speakers not only produce a merger, they also perceive it to the extent that even in linguistic research by Austrian linguists, the Bären and the BEEREN vowels are not investigated individually, since they are presumed to be fully merged (like Ehrlich, 2010; Moosmüller, 2007). The Bären vowel as such does not occur in the Austrian dialects either, and (unlike in Germany), a stylistic difference does not exist (cf. Muhr, 2007). Still, an orthographical difference is maintained for the two vowels. The present article observes a current reversal of this merger. This indicates that (1) speakers are aware of the difference between the vowels and (2) they know how the split should be made (provided they do it correctly, which is the case). But do speakers make the split on the basis of orthography only? Or do they rely on other - unknown - cues as well? And what is the motivation for the current reversal?

There are three aspects in the reversal to consider: (1) speakers have to be aware of the phonemic distinction between the BärEN and the BEEREN vowels, (2) speakers have to be motivated to undo the merger, and (3) speakers have to know how to make the distinction. I will argue that speakers know the phonemic distinction through orthography as well as the local dialects in Austria, although in the dialects, the pronunciation of the BäREN vowel differs from that in the standard variety. Second, the motivation for the unmerger is most plausibly the distinction that exists in the Northern Standard varieties (as spoken in 
Germany) - which is broadcasted through the media in Austria - and which most likely functions as the prestige variety. Crucially, however, in these northern varieties, much variation occurs as well. That is, in order to get the split right, Austrian speakers can neither fully rely on the distinction in their local dialects, nor on the distinction in the prestige varieties to which they orient themselves. Although the distribution in those varieties certainly play an important role in the current reversal of the merger, orthography is the clearest cue for getting the split right.

If it is indeed the case that spelling and contact with other varieties play a role in the change of a phonological system, phonological models should incorporate this information. Phonological feed-forward models do not allow for the influence of e.g. orthography. However, such non-grammatical information can be contained in the lexicon, as usage-based models and psycholinguistic models suggest. The way to model non-grammatical information in the lexicon, though, is also not straightforward. For instance, contact between different varieties does not necessarily influence the pronunciation of the standard variety. So, the question is which information is contained in the lexicon. Or, more specifically, is orthographic information stored in the lexicon? And why does this information make a difference only in particular cases (given that some sounds are represented by different spellings)? By examining the ongoing reversal of a merger (the BÄREN-BEEREN merger in the Austrian variety of Standard German) we will address these questions.

This article is structured as follows. The next section "From Distinction to Merger", outlines the historical development of the BäREN-BEEREN merger in Standard German and Austrian Standard German. The third section "The Polycentric Character of German" provides some background information about the different standard varieties in German. The fourth section presents the procedure used to investigate the current variation in the BÄREN-BEEREN merger. The fifth section contains the results. The final section contains the overall discussion and conclusion and considers the results within the Exemplar-theoretical framework.

\section{From Distinction to Merger}

This section considers the contrast between and merger of the BÄREN and BEEREN vowels through the ages, showing that a (near-) merger occurred in Standard German. Generally speaking, in Standard German, the pronunciation of the BärEN vowel is subject to extensive variation. The vowel - orthographically represented by $<\ddot{a}>$ or $<$ äh $>-$ may be pronounced as a long higher-mid unrounded front 
vowel [e:], or as a long lower-mid unrounded front vowel [ $\left.\varepsilon^{\mathrm{a}}\right]$, or any realization in between. We thus find the following variation (all forms here are Standard German):
(1) Bäder

$$
\mathrm{b}[\mathrm{e}:] \mathrm{der} \sim \mathrm{b}\left[\varepsilon_{\mathrm{i}}\right] \mathrm{der}
$$
'bath.PluR'
Bären
$\mathrm{b}[\mathrm{e}] \mathrm{ren}$
$\mathrm{b}[\varepsilon:] \mathrm{ren}$
'bear.PluR'

In case the pronunciation is the higher-mid vowel [e:], neutralization may occur with the BEEREN vowel (b[ex]ren 'berry.PLUR'), which is orthographically represented by $\langle\mathrm{e}\rangle$, $\langle\mathrm{ee}\rangle$ or $\langle\mathrm{eh}\rangle$. The pronunciation of the Bären vowel has been investigated in a number of studies (Hove, 2002; Kleiner \& Knöbl, 2011; König, 1989; Sloos, 2013; Spiekermann, 2008), which implicitly assume that the pronunciation of the BÄren vowel as [e:] indicates a merger with the BEEREN vowel. However, this is not necessarily the case: it is possible that both vowels are raised and a distinction is still made, and it is also possible that both vowels are pronounced lower and a distinction is still maintained. Theoretically speaking, it is even possible that the vowels are reversed, which is certainly not the case in the Standard variety, but possibly is in some dialects. This is beyond the scope of this paper and left for future investigation. This paper focuses on the conditions under which a merger or a split is made, in particular in the Austrian variety of Standard German.

It should be noted at this point that Standard German also has a short vowel $[\varepsilon]$, which can be orthographically represented by either $<$ ä $>$ or $<\mathrm{e}>$. This vowel is found in hält 'hold.3SG' and Held 'hero'. Interestingly, hält and Held are perfect homonyms (pronounced as [helt]) and as far as I know, no variation has been observed. This is the first indication that orthography can never be the only factor that drives the split of the BÄREN-BEEREN merger.

The Bären and BEEREN vowels were distinct phonemes in Old High German (OHG) with different sources and also different paths of development. We know that in OHG $<\ddot{a}>$ and $<\mathrm{e}>$ were pronounced differently since in poetry of that period $<$ e $>$ never rhymed with $<\ddot{a}>$ (Fourquet (1952:518) in Voyles (1991:171)). An important characteristic of a merger is generally a long period of confusion, or rather variation, between two sounds (Labov, 1994) and many current variation patterns seem to have a long sociolinguistic history (Milroy, 2004). Such long-term indecisiveness also arose in the BÄREN-BEEREN merger after the OHG period, when the distinction between the vowels gradually declined. This is reflected by the variation in the spelling. From 1350 until 1700, the usage of the grapheme $<\ddot{a}>^{1}$ increased and spread from Upper German across the whole German-speaking area (Moser et al., 1987:220). This spreading of the spelling < $<>$ for the BäREN vowel in itself is, of course, not a sign that the vowel was pronounced 
as a low vowel in those cases. Rather, it could be the case that the former spelling $<\mathrm{e}>$ indicated a pronunciation with a high vowel ([ex]) and the subsequent change to the grapheme $<\ddot{a}>$ indicated a prescriptive use of $[\varepsilon]$. This change in spelling occurred most frequently in the sixteenth century. During the seventeenth century, the opposite tendency set in: the grapheme $<$ ä $>$ was again gradually replaced by $<\mathrm{e}>$ (Moser, 1929: 150). This sudden reversal suggests that the pronunciation either went into the direction of [er] or that it was already pronounced as an [er] (and possibly did not change under the influence of the grapheme <ä $>$ at all). During the eighteenth century, confusion about the pronunciation was greatest. In an overview of the pronunciation of Standard German in the eighteenth century, Tritschler (1913) reports not only that written $<\mathrm{e}>$ was sometimes pronounced as [ع:], but also that written $<$ ä> was sometimes pronounced as [e:]. In the beginning of the twentieth century, Viëtor (1909) notes the decline of the BärENBEEREN distinction and predicted that a full merger would take place in favour of the BEEREN vowel. In the following section we will see that this prediction was not borne out.

Summarizing, after the OHG distinction between the Bären and the BEEREN vowel, an increasing tendency towards a merger set in, which could not be stopped by (prescriptive) spellings in the sixteenth century.

\section{The Polycentric Character of German}

Standard German is spoken in Germany, Austria, and Switzerland. Clear differences, both in pronunciation and lexicon, have been observed between the standard varieties in these three countries, and therefore German is traditionally considered as a polycentric language (Ammon, 1996; Clyne, 1991), or a language with different nationalects. One of the features that is clearly distinct in these nationalects is the pronunciation of the BÄREN vowel. This vowel has been investigated in a number of studies on Standard German in Germany and in Switzerland which reveal much variation: mergers do occur in the northern areas, but distinction is more common in the southern varieties including Switzerland (Hove, 2002; Kleiner \& Knöbl, 2011; König, 1989; Sloos, 2013; Spiekermann, 2008; Stearns \& Voge, 1979). Stylistic variation also occurs: in higher registers, [ $\left[\varepsilon^{\prime}\right]$ is more common (Mangold, 1994; Stearns \& Voge, 1979). Moreover, extensive variation is observed in the local dialects (Schmidt \& Herrgen, 2008, 2011).

As for Austrian Standard German, on the other hand, it is generally hold that the BäREN and BEEREN vowels are completely merged at the sound level (the orthographical distinction is also maintained in Austria). In an early paper, Abraham (1971:95) observes: 
"Zur Stützung des postulierten phonemischen Unterschieds zwischen /ä/ und /e/ werden Wortpaare wie wären/wehren angeführt; daneben wird sogar langes ä in Mänade und Präsenz gegenüber kurzem $\ddot{a}$ in Dämonen und Präsent beobachtet. Dieser Laut is jedenfalls für unsere Umgangssprache (auch sozial gehobener Klassen) phonemisch irrelevant..."

In support of the postulated phonemic distinction between /ä/ and /el, word pairs such as wären/wehren are provided, moreover, even a short-long opposition is observed in 'Mänade' and 'Präsenz'. In any case, this sound is phonemically irrelevant for our variety (viz. Austrian Standard German, author) (also for the socially upper classes) ...

Also Wiesinger (1996:156) postulates that a closed pronunciation (i.e. [er]) is common for the written long <ä> in Austrian German. Similarly, the Austrian Pronunciation Database and Austrian Dictionary (Muhr, 2007) provides the transcription [e:] for the BÄREN vowels in Austrian Standard German, whereas it transcribes the vowels as $\left[\varepsilon_{i}\right]$ in German Standard German. The latter transcription respects the stylistic difference in pronunciation in German Standard German (the dictionary is based on formal speech style), hence [ $\left.\varepsilon^{\mathrm{i}}\right]$ in German Standard German. The fact that the vowel is transcribed as [e:] in Austrian Standard German is consistent with the viewpoint that no stylistic differentiation in Standard Austrian German occurs.

The BÄREN-BEEREN merger in Austrian Standard German occurs across the board - in all speech varieties - such that the BÄREN vowel is considered the same as the BEEREN vowel; therefore, pronunciation studies (like Ehrlich, 2010; Moosmüller, 2007) do not even investigate them separately. Is the distinction made in the dialects? As for the Austrian dialects, the BÄrEn vowel sometimes appears to be realized as /a:/ (e.g. Šubrt (2010) on the Vienna dialect, Abraham (1971) on Montafon):

$\begin{array}{lll}\text { Austrian Standard German } & \text { German Standard German } & \text { gloss } \\ \text { Rad-l } & \text { Räd-chen } & \text { wheel.Dim } \\ \text { wa } & \text { wär } & \text { be.SuBj }\end{array}$

So in the dialects, a phonemic distinction between the BÄrEN and BEEREN vowels does occur, which may contribute to the awareness that these vowels are underlyingly distinct. However, the deviant pronunciation as a low vowel must lead to the conclusion that dialect levelling, if it would occur, is highly unlikely to directly affect the pronunciation of the BÄREN-BEEREN merger and reversal in Austrian Standard German, since other realizations are involved.

So for Austrian Standard German, the awareness of a phonemic distinction between the BäreN and BEEREN vowels may be enhanced by the phonemic 
distinction in the dialects as well as the graphemic distinction. However, the realization in the dialects does not correspond to that in other varieties of German, so it probably does not form a cue for a correct reversal of the merger. In order to get insight into the true nature of the merger and split of the BärEN and BEEREN vowels in Austrian Standard German, the following sections present an acoustic analysis of corpus data of spontaneous speech.

\section{Procedure}

This section provides background information about the data, and explains the methodology of the acoustic measurements and the statistical procedure that provides insight into the degree of merger of the BäREN and BEEREN vowel. We will successively discuss the data, the measurement of the vowels in Praat, the normalization procedure, and the statistical procedure to obtain the speaker means in the degree of their merger (Pillai scores).

\section{The Data}

We investigated the current pronunciation of the BÄREN and BEEREN vowel in colloquial Standard German in Austria. The data for this study are part of the corpus of spoken Standard German, Deutsch Heute 'German Today', which has been collected at the Institut für Deutsche Sprache in Mannheim (IDS, Project Variation des gesprochenen Deutsch 'Variation in spoken German' (Brinckmann, Kleiner, Knöbl, \& Berend, 2008). The recordings of the corpus were made between 2006 and 2009. For this study, we investigated all locations in Austria for which older and younger speakers were recorded, namely, six sites (Bludenz, Eisenstad, Leoben, Lienz, Linz, Vienna). Per location, four students at a local secondary school were interviewed, two females and two males, aged between sixteen and nineteen. In addition, one female and one male speaker aged between fifty and sixty were recorded. In total, 33 speakers were analysed. Only biographic interviews were used with spontaneous speech data on fixed topics, such as dialect preferences, occupational background (older speakers), and leisure time (younger speakers). Each interview lasted for 30-45 minutes and was annotated in standard spelling in Praat (Boersma \& Weenink, 2010). In sum, the data contained 393 unambiguous cases of the BÄrEN vowel, which were analyzed for the present study (an average of 11.2 per speaker). ${ }^{2}$ Another six BEEREN vowels per speaker were analysed. 


\section{Measuring the BÄREN and the BEEREN Vowel}

In order to be able to compare the pronunciation of the vowels, their pronunciation have to be quantified in a unified way. The vowels [e: and $\left[\varepsilon^{*}\right]$ differ from each other in height, viz. [e:] is higher than [ع:]. A small difference in frontness also occurs: [er] is slightly more fronted than [ $\left[\varepsilon^{2}\right]$. Differences in the high-low dimension are reflected in the first formant $(F 1)$ of the vowels, whereas differences in the front-back dimension correspond to the value of the second formant $(F 2)$. This is shown in Figure 1, where the values of $F 1$ and $F 2$ are provided in Hertz $(\mathrm{Hz})$.

The Praat speech processing software (Boersma \& Weenink, 2010) was used to create spectrograms and the steady state of the vowels was manually segmented. The steady state is defined as the period in which $F 1$ and $F 2$ are stable, i.e. are not in a transition phase with an adjacent sound or, in other words, do not show coarticulation (note that neither the BÄREN vowel nor the BEEREN vowel diphthongizes). Formant tracks were automatically computed by using the Burg LPC algorithm in Praat. The tracks were manually corrected if a visual mismatch between the formant tracks and the formant bands in the spectrogram was observed. Since the vowels that were measured almost always had a clear steady state (i.e. stable $F 1$ and $F 2$ ), that is, they were truly monophthongs, it sufficed to measure the temporal midpoint of the vowels. This temporal midpoint and the $F 1$ and F2 were measured by using a Praat script. ${ }^{3}$ To compare the Bären vowel with the BEEREN vowel, three prototypical realizations of the BEEREN vowel (i.e. accented

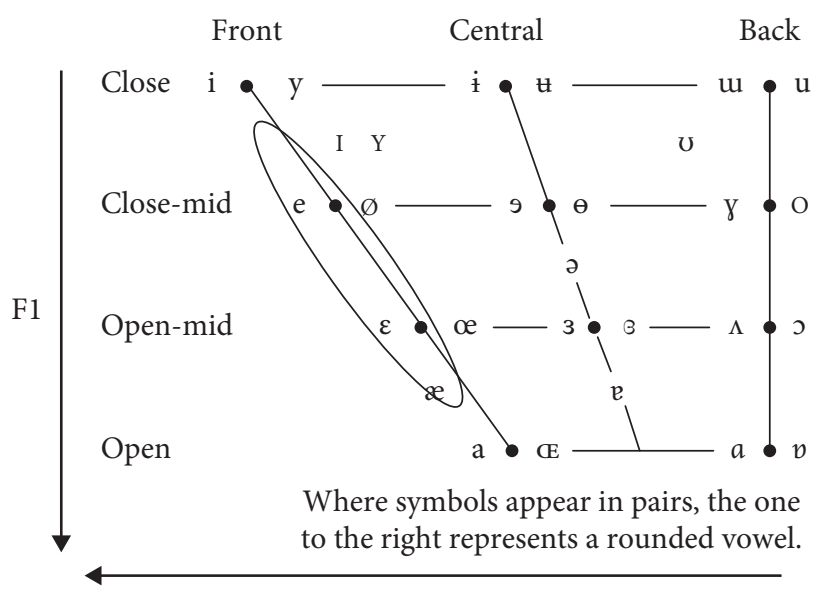

F2

Figure 1. Vowel space diagram. F1 corresponds to the vowel height and F2 corresponds to the frontness of the vowel. 
vowels in content words that do not undergo raising or lowering due to context) were measured for each speaker. Since German mid front vowels are often lowered before -r (Hall, 1993; König, 1989; Sloos, 2013), three more realizations per speaker of the BEEREN vowel were measured in pre-r context. ${ }^{4}$

\section{Vowel Normalization}

The vowels in the data show much variation, caused by different factors: physiological differences between the speakers, phonological merger and distinction, and sociolinguistic and dialectal influences. In order to eliminate the physiological differences, but maintain the phonological and sociolinguistic differences, a normalization procedure is common in studies of this type. Here we used the Fabricius and Watt normalization technique, conducted with the package \{vowels\} in the R statistical analysis environment (Fabricius, Watt, \& Johnson, 2009; Thomas \& Kendall, 2007; Watt \& Fabricius, 2002). On the basis of the maximal vowel space of each speaker, this normalization procedure calculates the individual centre of gravity in the oral cavity and transforms the $F 1$ and $F 2$ for each token accordingly. The interested reader is referred to Fabricius et al. (2009) and Watt \& Fabricius (2002) for details about this procedure.

\section{Pillai-Scores as a Degree of Merger}

Subsequently, to obtain a value for the degree of merger, the data were analysed for their Pillai score, which is a measure for the degree of merger (Hall-Lew, 2010). The Pillai score is the result of a MANOVA test on the difference between the normalized tokens of two vowel types, providing a score for each speaker. In the Pillai score, information about the difference between the two vowels is maintained. The Pillai score can also neutralize for phonological context. Moreover, the Pillai score allows for the use of unbalanced (interview/conversation) data (Hall-Lew, 2010). The higher the Pillai score, the larger the distinction between the two vowels for the speaker. Significant scores $(p \leq 0.05)$ were taken as evidence for a distinction. In the computation of the Pillai score, the phonological environment was taken into account (i.e. the sound following the vowels). Thus, the Pillai score is used as an indication for the degree of merger and distinction. 


\section{Results}

All Pillai scores are contained in the Appendix. Among the 34 speakers, only six made a distinction. Five of them belonged to the younger generation. The only older speaker who made the split was from Bludenz, close to the Swiss border, where the Alemannic dialect is spoken, in which a low Bären vowel is common and which sometimes influences the pronunciation in the standard variety (see Sloos, 2013: 109-126). After we obtained the Pillai scores, we used them for cartographical purposes. In order to investigate change in progress, separate analyses were made for older and younger speakers (since we assume that younger speakers are more inclined to use the innovative sounds and older speakers retain the pronunciation to which they are used (e.g. Labov 2001; Milroy \& Milroy 1985)).

For each speaker, the Pillai score indicates whether a merger or a distinction was made: the value 1 was assigned if she merged the BÄrEN and BEEREN vowel and the value 2 was assigned if she made a distinction between the BÄREN and BEEREN vowel. Subsequently, for each location, these scores were averaged for the older speakers and the younger speakers separately. To visualize the areal distribution of merger and distinction, maps were produced, using the $\mathrm{R}$ packages maps (Becker \& Wilks, 2011b), mapdata (Becker \& Wilks, 2011a), and geoR (Ribeiro Jr \& Diggle, 2001). Isoglosses were estimated by the software and indicate the proportion of speakers who merge the vowels vs. speakers who distinguish the

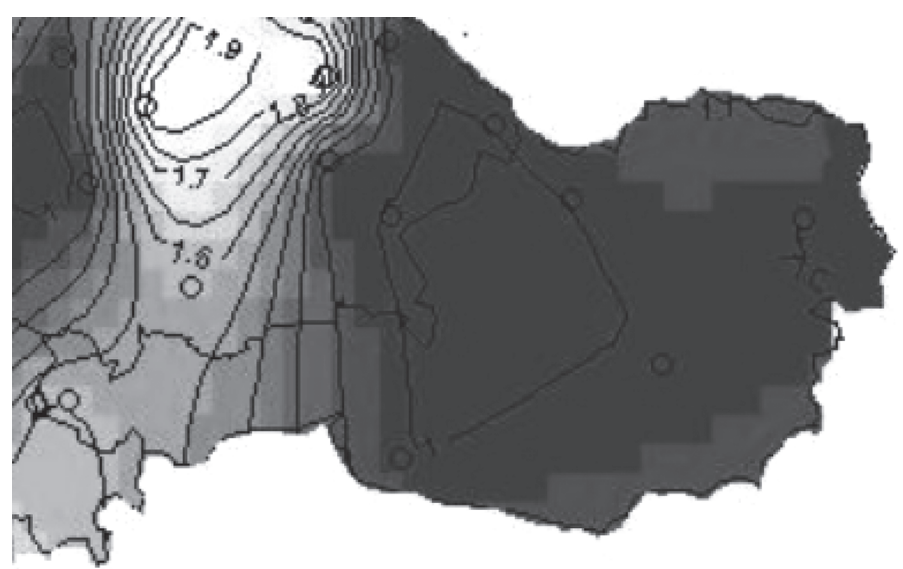

Figure 2. Neutralization and distinction within the older speakers: dark areas correspond with relatively many speakers who merge the BärEN and BEEREN vowels and the light areas correspond with relatively many speakers who distinguish in the production of the Bären and BEEREN vowels. Further see text. 


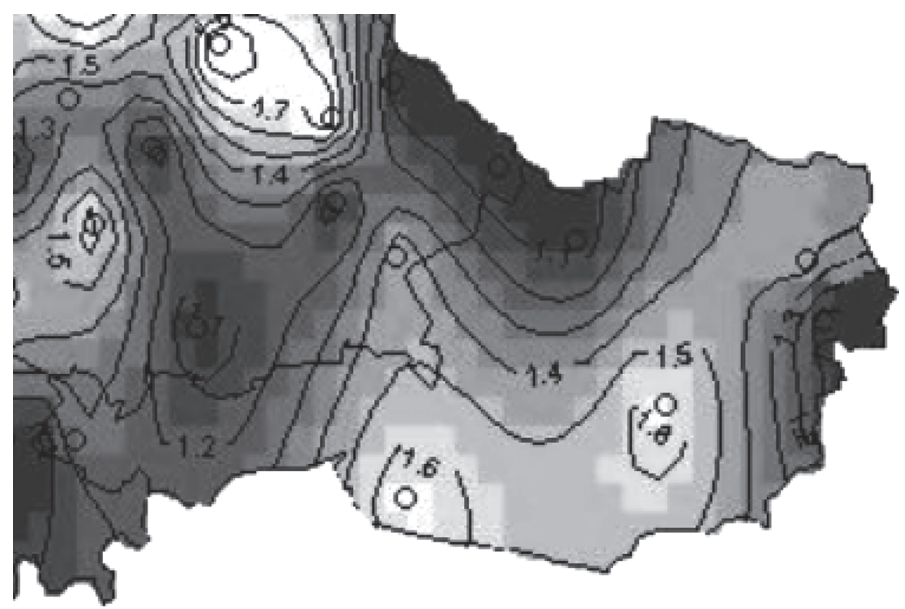

Figure 3. Neutralization and distinction within the younger speakers: dark areas correspond with relatively many speakers who merge the B̈̈REN and BEEREN vowels and the light areas correspond with relatively many speakers who distinguish in the production of the Bären and BEEREN vowels. Further see text.

vowels on a scale of 1 (only merged, relatively dark) to 2 (only distinction, relatively light).

Figure 2 shows the results for the older speakers. As expected, the map displays a merger in Austrian Standard German (relatively dark). Figure 3 shows the results for the younger speakers, which displays more of a split in the younger speakers. So the younger speakers make a split more often than the older speakers do, thus it appears that an ongoing split, or reversal of the merger, occurs.

\section{General Discussion and Conclusions}

We investigated the pronunciation of the BÄREN and the BEEREN vowel in Standard German in terms of merger and split. In OHG, these vowels were distinctive, which was followed by a long period of ongoing merger. The results of this paper revealed an ongoing reversal of that merger in Austria. This is remarkable, since it is commonly assumed that no distinction in the pronunciation occurred in Austrian. Although awareness of the phonemic distinction may exist on the basis of a distinction in the dialects and in orthography, this is certainly not enough for a reversal to occur. Which could be the motivation for the merger reversal? Whatever the answer is, it must be unrelated from the distinction in the dialects and orthography, since (1) the distinction in the dialects involves other vowels than the ongoing reversal observed in the standard variety and (2) the short vowels 
with the same orthographic representations in the homophonous hält/Held pair do not undergo the split.

The answer has to be sought in the pluricentric character of German, discussed above. In a pragmatic study on the influence of German Standard German on Austrian Standard German through television broadcasting, Muhr (1995, 2003) argues that Austrians are gradually more and more inclined to orient themselves to the standard variety as it is spoken in Germany. Austrian-German language contact occurs under the influence of tourism, mass media, and economical co-operation, and shows a lexical and grammatical shift in Standard Austrian German towards Standard German as spoken in Germany. I am not aware of pronunciation studies regarding the accommodation of the Austrians towards the standard variety in Germany. But in general, grammatical changes occur relatively late in contact situations, pronunciation being affected earlier. Adaptation of the pronunciation in Austrian Standard German is therefore expected. This idea is supported by the findings of Hove (2002), who demonstrates that younger speakers in Switzerland, under the influence of the media, adopt a pronunciation that is more like German Standard German. Hove (2002) found a more positive attitude toward the variety in Germany among younger Swiss speakers than to their own Standard Swiss German variety, which they tend to regard as inferior. Similarly, I would suppose that the pronunciation in Austrian Standard German among younger speakers is influenced by German Standard German, which they consider to be the prestige variety.

Since, as has been shown in previous studies about the Bären vowel (Hove, 2002; Kleiner \& Knöbl, 2011; König, 1989; Sloos, 2013; Spiekermann, 2008; Stearns \& Voge, 1979), a BÄREN-BEEREN distinction does occur in formal registers in German Standard German and to a lesser extent in the colloquial standard variety, here we may find a motivation for the Austrian speakers to reverse the BÄrEN-BEEREN merger. So, since German Standard German functions as the prestige variety, we may expect the Austrian speakers to orient themselves toward that variety in their pronunciation of the BÄREN vowel as well. This motivation in itself, however, does not guarantee the correct reversal of the BÄREN-BEEREN merger in Standard Austrian German. As the previous studies have shown, the pronunciation of the BÄREN vowel, in Germany, is subject to extensive variation. Thus the Austrian speakers get a variable input for the BärEN vowel: sometimes it is merged with the BeEREN vowel, sometimes it is not. On the basis of this variable input - which hinges on style, lexical frequency, pre-r context, regiolectal variation, and a more general tendency to unmerge (see Sloos, 2013) - it is not easy for the Austrian listener to figure out the correct pronunciation of the BÄrEN-BEEREN vowels. Thus, although the pronunciation in German Standard 
German can function as a motivation for reversal, in order to get the split right, the German Standard variety itself is not a very reliable source. ${ }^{5}$

Summarizing so far, we conclude that younger speakers of Austrian Standard German orient themselves toward the German Standard German variety and we suppose that, under the influence of that prestige variety, they make a distinction between the BÄREN and BEEREN vowels which were previously merged in their native variety (as the older speakers' data showed, recall Figure 2). However, since the BÄrEN vowel is variable in German Standard German, it is rather unlikely that Austrian speakers get the split right on the basis of this language contact. The correct distribution of the BÄrEN and the BEEREN vowels may be based on the phonemic distinction in the dialects, but note that the dialectal pronunciation differs from that in the standard variety. Phonemic awareness may be strengthened by the distinction maintained in the orthography. This is the only consistent source for the distinction. However, orthography alone cannot be the cause of the reversal either (since no distinction is made between the graphemes $<\ddot{a}>$ and $<\mathrm{e}>$ where they represent the short vowel); therefore, I suppose that the combination of contact with the prestige variety together with orthography are responsible for the BÄREN-BEEREN reversal.

One of the questions posed in the first section addressed the lexical storage of the sounds that are involved in the reversal of a merger. Sound change is not part of the phonological grammar proper (although sound change may eventually lead to grammatical change, which can be modelled in generative grammar). The results can probably best be modelled in Exemplar Theory (ET), which can account for the sound change and also the mental representations of the words (Bybee, 1999; Johnson, 1997). In ET, each instantiation of a word is stored in the mental lexicon as an exemplar. Storage occurs on the basis of similarity, such that more similar exemplars are stored in exemplar categories. Categorization is word-based. Different categories are connected on the basis of analogical relations between words.

In ET, production depends on neural activation, that is, the most highly activated exemplars are selected for pronunciation. In variation, similar exemplars or exemplar categories may compete with each other and the strongest is selected for production. If no decision can be made on the basis of purely linguistic information, other information may be invoked. Hay et al. (2006) suggest that in case of equal competition between different exemplars - but not otherwise - speakers may rely on other cues; for instance, social information. This implies that sociolinguistic information is stored alongside the pronunciation of the word. I would like to suggest that if social cues are lacking, or if social cues also do not lead to a decision, speakers may in addition rely on orthographic information. 
Consequently, information about spelling must also be stored in exemplars. Orthographical information becomes available as a cue for pronunciation if, and only if, linguistic as well as social information fall short in the selection process. The latter assumption is necessary since orthographical information alone cannot warrant a certain pronunciation: recall that notwithstanding the orthographic difference between $<\ddot{a}>$ and $<\mathrm{e}>$ where it represents a short vowel, no variation occurs; and despite the former (prescriptive) use of the grapheme $<$ ä $>$, especially in the sixteenth century, the BÄREN-BEEREN merger still proceeded. Orthography therefore only seems to be invoked by more or less conscious intervention. I would therefore suggest that orthography - also because it is learned separately and memorized consciously, unlike auditory information - is stored at another category level, which is, of course, connected to the auditory level. Like the other parts of the lexicon, the categories at the orthographic level must be formed on the basis of words and connected to the auditory level on a word-by-word basis. The viewpoint that there is a direct connection between the auditory and visual representations of words is supported by cross-modal priming studies, which reveal that auditory perception primes visual activation and visual priming leads to auditory activation (Swinney, 1979 and much subsequent work).

The findings in this article are also perfectly in line with recent psycholinguistic results in which an independent effect of orthography cannot be found, but in which spelling seems to have an influence on pronunciation in combination with other factors. In a lexical decision task, Cutler, Treiman and van Ooijen (2010) found that reaction times of non-words are longer if they contain sounds that can be spelled in multiple ways. Crucially, the effect only occurs if filler words also contain phonemes that can be spelled in multiple ways, but it disappears if fillers consist of only unambiguous spellings. Also in production experiments, orthographical influence on pronunciation has been reported. Again, if orthography is the only factor that could influence the pronunciation, a null effect is found, but if memorization also plays a role in the task, orthographical influence may occur (Alario, Perre, Castel, \& Ziegler, 2007). These results show, similar to the corpus study reported in this paper, that orthographical influence on pronunciation combines with other factors and cannot be the only factor that drives pronunciation into a particular direction. This supports the viewpoint that orthographical information is stored in the lexicon, but in a different way than auditory information, that the visual and auditory representations are connected on a word-by word basis, and that orthographic information is only retrieved if other cues are lacking.

To conclude, this paper showed that a reversal of a merger can occur if there is a sociolinguistic motivation for the reversal and that speakers get the split right if they can rely on a distinction in the orthography. This has some implications for 
Exemplar Theoretical modelling, but more research on the influence of orthography and sociolinguistic factors on the pronunciation is certainly warranted to optimize the model. Also, the exact pronunciation of the BEEREN and BÄREN vowels in Austrian Standard German among younger speakers is left for further research. An intriguing question that requires more investigation concerns the orientation of the Austrian and Swiss speakers toward the prestige variety in Germany in relation to the pronunciation of the BEEREN and BÄREN vowels. The same orientation works out into different directions. Whereas in Austrian Standard German, the old situation was a merger and a current reversal is observed, Swiss Standard German shows the opposite: a former distinction is currently merged. We will investigate this in the near future.

\section{Acknowledgements}

This research was made possible by a DFG grant, project 1624/1 'Frequency Effects in Language. The corpus material was made available to the author by Stefan Kleiner of the Institut für deutsche Sprache, Mannheim, which is gratefully acknowledged. This paper benefitted much from the comments on an earlier version of Jeroen van de Weijer and two anonymous reviewers.

\section{Notes}

1. Originally, the grapheme consisted of an $<\mathrm{a}\rangle$ with a small $<\mathrm{e}\rangle$ on top of it, which later developed into $<\ddot{a}>$.

2. In general, vowel length is unambiguous, except in Städte 'town.PLUR' and nächst 'next'. Therefore the respective lemmas are excluded from analysis.

3. I am grateful to Jos Pacilly (Leiden University) for providing the Praat script to me.

4. Six BEEREN vowels per speaker might seem not enough, compared to the number of BäREN vowels, but the reader should keep in mind that the Bären vowel is subject to extensive variation, which is not the case for the BEEREN vowel.

5. One might wonder whether hypercorrection does occur in the sense that the BEEREN vowel also lowers to $[\varepsilon]$. The data do not provide evidence for that.

\section{References}

Abraham, W. (1971). Das Vokalsystem der Mundart des Montafons. Zeitschrift Für Dialektologie Und Linguistik, 38(1), 95-120. 
Alario, F. X., Perre, L., Castel, C., \& Ziegler, J. C. (2007). The role of orthography in speech production revisited. Cognition, 102(3), 464-475.

Ammon, U. (1996). On comparing the centers of plurinational languages: The example of German. In M. Hellinger \& U. Ammon (Eds.), Contributions to the sociology of language (pp. 17-36). Berlin: Walter de Gruyter.

Becker, R. A., \& Wilks, A. R. (1993). Maps in S. AT\\&T Bell Laboratories Statistics Research Report, 93(2).

Becker, R. A., \& Wilks, A. R. (1995). Constructing a geographical database. AT\\&T Bell Laboratories Statistics Research Report, 95(2).

Boersma, P., \& Weenink, D. (2010). Praat: Doing phonetics by computer. [computer program].

Brinckmann, C., Kleiner, S., Knöbl, R., \& Berend, N. (2008). German today: An areally extensive corpus of spoken Standard German. Proceedings of the Sixth International Conference on Language Resources and Evaluation, Marrakech, Marocco, 3185-3191.

Bybee, J. L. (1999). Usage-based phonology. Functionalism and Formalism in Linguistics, 1, 211-242.

Clyne, M. (1991). German as a pluricentric language. In M. Clyne (Ed.), Pluricentral languages. Differing norms in different nations (pp. 117-148). Berlin: Mouton de Gruyter.

Cutler, A., Treiman, R., \& van Ooijen, B. (2010). Strategic deployment of orthographic knowledge in phoneme detection. Language and Speech, 53(3), 307-320.

Ehrlich, K. (2010). Die Aussprache des österreichischen Standarddeutsch: Umfassende Sprech-und Sprachstandserhebung der österreichischen Orthoepie. $\mathrm{PhD}$ dissertation, Universität Wien.

Fabricius, A., Watt, D., \& Johnson, D. E. (2009). A comparison of three speaker-intrinsic vowel formant frequency normalization algorithms for sociophonetics. Language Variation and Change, 21, 413-435.

Hall, T. A. (1993). The phonology of German /R/. Phonology, 10(1), 83-105.

Hall-Lew, L. (2010). Improved representation of variance in measures of vowel merger. Proceedings of Meetings on Acoustics, Baltimore: Maryland, 127(3), 060002-060012.

Hay, J., Warren, P., \& Drager, K. (2006). Factors influencing speech perception in the context of a merger-in-progress. Journal of Phonetics, 34(4), 458-484.

Hove, I. (2002). Die Aussprache der Standardsprache in der deutschen Schweiz. Tübingen: Niemeyer.

Johnson, K. (1997). Speech perception without speaker normalization: An exemplar model. In K. Johnson \& J. W. Mullennix (Eds.), Talker variability in speech processing (pp. 145-165). San Diego: Academic Press.

Kleiner, S., \& Knöbl, R. (2011). Hochdeutsch und Hochdeutsch: Regionale Gebrauchsstandards im gesprochenem Deutsch (No. Sprachreport 2). Mannheim: Institut für Deutsche Sprache.

König, W. (1989). Atlas zur Aussprache des Schriftdeutschen in der Bundesrepublik Deutschland. Ismaening: Max Hueber Verlag.

Labov, W. (1994). Principles of linguistic change: Internal factors. Massachusetts and Oxford: Wiley-Blackwell.

Labov, W. (2001). Principles of linguistic change: Social factors. Malden and Oxford: Blackwell.

Maguire, W. N. (2008). What is a merger, and can it be reversed? The origin, status and reversal of the 'NURSE-NORTH Merger' in Tyneside English. PhD dissertation, Newcastle University.

Mangold, M. (1994). Duden Aussprachewörterbuch. Mannheim: Duden Verlag.

Milroy, L. (2004). An essay in historical sociolinguistics?: On Donka Minkova’s "Philology, linguistics, and the history of $[\mathrm{hw}] \sim[\mathrm{w}]$. Studies in the History of the English Language II: Unfolding Conversations, 2, 47. 
Milroy, J., \& Milroy, L. (1985). Linguistic change, social network and speaker innovation. Journal of Linguistics, 21(2), 339-384.

Moosmüller, S. (2007). Vowels in standard Austrian German. Unpublished habilitation, University of Vienna.

Muhr, R. (1995). Zur Sprachsituation in Österreich und zum Begriff "Standardsprache" in plurizentrischen Sprachen. Sprache und Identität in Österreich. In R. Muhr, R. Schrodt \& P. Wiesinger (Eds.), Österreichisches Deutsch. Linguistische, sozialpsychologische und sprachpolitische Aspekte einer nationalen Variante des Deutschen (pp. 75-110). Wien: Verlag Hölder-Pichler-Tempsky.

Muhr, R. (2003). Language change via satellite: The influence of German television broadcasting on Austrian German. Journal of Historical Pragmatics, 4(1), 103-127.

Muhr, R. (Ed.). (2007). Österreichisches Aussprachewörterbuch und Österrreichische Aussprachedatenbank. Frankfurt/M. / Wien: Peter Lang Verlag.

Ribeiro, P. J. Jr., \& Diggle, P. J. (2001). GeoR: A package for geostatistical analysis. R-NEWS, R-NEWS, 1(2), 15-18.

Schmidt, J. E., \& Herrgen, J. (2008). Digitaler Wenker-Atlas (DiWA). http://www.diwa.info/

Schmidt, J. E., \& Herrgen, J. (2011). Sprachdynamik: Eine Einführung in die moderne Regionalsprachenforschung. Berlin: Erich Schmidt Verlag.

Sloos, M. (2013). Frequency and phonological grammar: An integrated approach. Evidence from German, Indonesian, and Japanese. PhD dissertation, University of Groningen.

Spiekermann, H. (2008). Sprache in Baden-Württemberg: Merkmale des regionalen Standards. Tübingen: Max Niemeyer Verlag.

Stearns, M. J., \& Voge, W. (1979). The contemporary pronunciation of long <ä> in Modern Standard German: A data-based, computer-assisted analysis. In J. Köster (Ed.), Hamburger Phonetische Beiträge. Untersuchungen zur Phonetik und Linguistik. Miszellen VI (pp. 127181). Hamburg: Helmut Buske Verlag.

Šubrt, P. (2010). Wiener Dialekt. Unpublished MA thesis, Masaryk University of Brünn.

Swinney, D. A. (1979). Lexical access during sentence comprehension: (Re) consideration of context effects. Journal of Verbal Learning and Verbal Behavior, 18(6), 645-659.

Thomas, E. R., \& Kendall, T. (2007). NORM: The vowel normalization and plotting suite. An online tool for sociophonetic vowel normalization. http://ncslaap.lib.ncsu.edu/tools/norm/.

Tritschler, A. (1913). Aussprache des Neuhochdeutschen im 18. Jahrhundert. Beiträge zur Geschichte der deutschen Sprache und Literatur (PBB), 38, 373-458.

Trudgill, P., \& Foxcroft, T. (1978). On the sociolinguistics of vocalic mergers: Transfer and approximation in East Anglia. Sociolinguistic Patterns in British English, 69-79.

Viëtor, W. (1909). Die Aussprache des Schriftdeutschen. Mit dem Wörterverzeichnis der amtlichen "Regels für die deutsche Rechtschreibung in phonetischer Umschrift sowie phonetischen Texten". Wien: Edition Praesens.

Voyles, J. (1991). A history of OHG i-umlaut. In K. Grubmüller, M. Reis, \& B. Wachinger (Eds.), Beiträge zur Geschichte der deutschen Sprache und Literatur (pp. 159-194). Tübingen: Max Niemeyer Verlag.

Watt, D., \& Fabricius, A. (2002). Evaluation of a technique for improving the mapping of multiple speakers' vowel spaces in the F1 F2 plane. In D. Nelson (Ed.), Leeds Working Papers in Linguistics and Phonetics (pp. 159-173). Leeds: University of Leeds.

Wiesinger, P. (1996). Das österreichische Deutsch als eine Varietät der deutschen Sprache. Die Unterrichtspraxis/Teaching German, 29(2), 154-164. 


\section{Appendix}

Pillai scores and their significance value for all speakers. Pillai scores with a significance value $>0.05$ are treated as distinction and Pillai scores with a significance value $<0.05$ are treated as a neutralization.

\begin{tabular}{|c|c|c|c|c|c|}
\hline Location & Speaker & Age & Merger/Split & Pillai & Significance \\
\hline \multirow[t]{6}{*}{ Bludenz } & 1 & young & NEUTRALIZATION & 0.007 & 0.979 \\
\hline & 2 & young & DISTINCTION & 0.749 & 0.004 \\
\hline & 3 & young & NEUTRALIZATION & 0.187 & 0.661 \\
\hline & 4 & young & NEUTRALIZATION & 0.320 & 0.260 \\
\hline & 5 & older & DISTINCTION & 0.530 & 0.011 \\
\hline & 6 & older & NEUTRALIZATION & 0.507 & 0.020 \\
\hline \multirow[t]{6}{*}{ Eisenstadt } & 1 & young & NEUTRALIZATION & 0.110 & 0.498 \\
\hline & 2 & young & NEUTRALIZATION & 0.047 & 0.563 \\
\hline & 3 & young & NEUTRALIZATION & 0.039 & 0.684 \\
\hline & 4 & young & NEUTRALIZATION & 0.157 & 0.278 \\
\hline & 5 & older & NEUTRALIZATION & 0.396 & 0.133 \\
\hline & 6 & older & NEUTRALIZATION & 0.199 & 0.514 \\
\hline \multirow[t]{5}{*}{ Leoben/Liezen } & 1 & young & DISTINCTION & 0.340 & 0.016 \\
\hline & 2 & young & NEUTRALIZATION & 0.073 & 0.527 \\
\hline & 3 & young & DISTINCTION & 0.354 & 0.030 \\
\hline & 4 & older & NEUTRALIZATION & 0.121 & 0.773 \\
\hline & 5 & older & NEUTRALIZATION & 0.082 & 0.741 \\
\hline \multirow[t]{5}{*}{ Lienz } & 1 & young & DISTINCTION & 0.653 & 0.025 \\
\hline & 2 & young & DISTINCTION & 0.458 & 0.034 \\
\hline & 3 & young & NEUTRALIZATION & 0.306 & 0.193 \\
\hline & 4 & older & NEUTRALIZATION & 0.006 & 0.972 \\
\hline & 5 & older & NEUTRALIZATION & 0.029 & 0.877 \\
\hline \multirow[t]{6}{*}{$\operatorname{Lin} z$} & 6 & young & NEUTRALIZATION & 0.006 & 0.948 \\
\hline & 1 & young & NEUTRALIZATION & 0.061 & 0.778 \\
\hline & 2 & young & NEUTRALIZATION & 0.427 & 0.188 \\
\hline & 3 & young & NEUTRALIZATION & 0.436 & 0.057 \\
\hline & 4 & older & NEUTRALIZATION & 0.084 & 0.347 \\
\hline & 5 & older & NEUTRALIZATION & 0.511 & 0.117 \\
\hline \multirow[t]{6}{*}{ Wien } & 1 & young & NEUTRALIZATION & 0.016 & 0.845 \\
\hline & 2 & young & NEUTRALIZATION & 0.189 & 0.351 \\
\hline & 3 & young & NEUTRALIZATION & 0.025 & 0.939 \\
\hline & 4 & older & NEUTRALIZATION & 0.374 & 0.060 \\
\hline & 5 & older & NEUTRALIZATION & 0.228 & 0.144 \\
\hline & 6 & older & NEUTRALIZATION & 0.216 & 0.334 \\
\hline
\end{tabular}




\section{Corresponding Address}

Marjoleine Sloos

Interactive Minds Centre

Jens Chr. Skous Vej 4, Building 1483, 3rd floor

DK-8000 Aarhus C, Denmark

marj.sloos@gmail.com 